\title{
Utility of plasma galectin-3 in predicting long-term mortality in patients with acute heart failure
}

\author{
Hoang Van Sy ${ }^{1,2, *}, \#$, Dang Quang Toan ${ }^{2, \#}{ }^{\circledR}$, Ta Thi Thanh Huong ${ }^{1}$, Chau Ngoc Hoa $^{1}$, Tran Kim Trang ${ }^{1}$
}

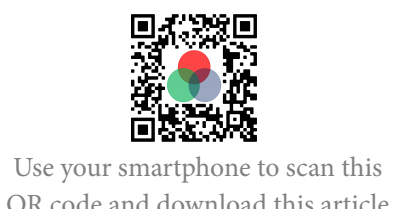

QR code and download this article

\#contributed equally to this work

${ }^{1}$ Department of Internal Medicine, University of Medicine and Pharmacy at Ho Chi Minh City, Ho Chi Minh City, Vietnam

${ }^{2}$ Department of Cardiology, Cho Ray hospital, Ho Chi Minh City, 70000,

Vietnam

Correspondence

Hoang Van Sy, Department of Internal Medicine, University of Medicine and Pharmacy at Ho Chi Minh City, Ho Chi Minh City, Vietnam

Department of Cardiology, Cho Ray hospital, Ho Chi Minh City, 70000, Vietnam

Email: hoangvansy@ump.edu.vn

History

- Received: Jan 24, 2021

- Accepted: Apr 15, 2021

- Published: Apr 29, 2021

DOI : 10.15419/bmrat.v8i4.669

\section{Check for updates}

\section{Copyright}

( $)$ Biomedpress. This is an openaccess article distributed under the terms of the Creative Commons Attribution 4.0 International license.

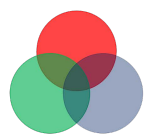

\begin{abstract}
Background: Several studies have investigated Galectin-3 as a promising biomarker for predicting the short-term and long-term mortality of patients with acute heart failure. This study aimed to examine the usefulness of plasma galectin-3 at the time of admission in predicting long-term mortality in Vietnamese patients with acute heart failure (AHF). Methods: We carried out a cohort study including 117 patients consecutively diagnosed with acute heart failure in a single cardiology department. Plasma galectin-3 and other biomarkers were measured at the time of admission. The patient's clinical and analytical characteristics were recorded. The main endpoint was oneyear all-cause mortality. Results: There were six patients (5\%) lost to follow-up and 59 patients (53.2\%) reaching primary outcome within one year after hospital admission. The median plasma galectin-3 level $(\mathrm{ng} / \mathrm{mL})$ in patients with acute heart failure was 34.6 (26.7 - 44.1). Plasma galectin-3 in the alive group was significantly higher than that in the deceased group at one-year follow-up. In predicting one-year all-cause mortality, galectin-3 had an area under the curve (AUC) of 0.71 (95\% confidence interval $(\mathrm{CI}), 0.62-0.81$ ), representing a good prognostic factor, while brain natriuretic peptide (BNP) and troponin I were inferior to galectin-3 with an AUC of $0.69(95 \% \mathrm{Cl}, 0.59-$ 0.79 ) and $0.63(95 \% \mathrm{Cl}, 0.53-0.74)$, respectively. The optimal cut-off value for galectin-3 was 40.75 $\mathrm{ng} / \mathrm{mL}$ with a sensitivity of $50.1 \%$ and a specificity of $88.5 \%$. In a multivariate model, patients with galectin-3 levels $>40.75 \mathrm{ng} / \mathrm{mL}$ had a hazard ratio $(\mathrm{HR})$ of $2.8(95 \% \mathrm{Cl}, 1.5-5 ; \mathrm{p}=0.001)$. The best prediction model was the combined model of galectin-3 and BNP, yielding an AUC of 0.78 (95\% $\mathrm{Cl}, 0.70-0.86 ; \mathrm{p}<0.001)$. Conclusions: Our study suggested that galectin-3 levels could predict long-term all-cause mortality in patients with acute heart failure with a good prognostic capacity. Combining galectin-3 and BNP could yield better risk stratification.
\end{abstract}

Key words: Acute Heart Failure, Biomarkers, Galectin-3, Mortality, Prognosis

\section{INTRODUCTION}

It is estimated that 26 million people worldwide live with heart failure, which represents a global health problem. It is also expected that this number will rapidly increase due to the population aging in general and the growing prevalence of comorbidities ${ }^{1}$. Over the past decade, the utilization of different biomarkers in evaluating heart failure has gained an essential clinical value, and serves as an essential tool for diagnosis, prognosis, and even therapy-guiding or decision making ${ }^{2}$. Accordingly, the use of natriuretic peptides including brain natriuretic peptide (BNP) or Nterminal pro-brain natriuretic peptide (NT-proBNP) were recommended at class IA in the current American and European guidelines for heart failure, for either diagnostic or prognostic purposes ${ }^{3,4}$. Although they have an excellent ability to differentiate and identify acute heart failure patients, the prognostic capacity of natriuretic peptides remains average. Moreover, natriuretic peptides values are affected greatly by several factors, such as age, renal function, and obesity status ${ }^{5-7}$. Therefore, novel biomarkers are being studied with the aim of adding benefits with respect to prognostication and risk stratification.

Galectin-3 is a soluble beta-galactoside binding protein produced predominantly by activated fibroblasts and macrophages and serves as a pro-fibrotic and pro-inflammatory biomarker ${ }^{8}$. Galectin-3 initiates the fibrotic process by activating macrophages and fibroblasts, resulting in the release of several pro-inflammatory molecules, leading to tissue injury, inflammation, enhanced collagen deposition, and extra-cellular matrix adhesion ${ }^{9}$. The role of galectin3 in heart failure was first reported by Sharma et al. The injection with galectin-3 into the pericardial sac of normal rats resulted in cardiac remodeling with cardiac dysfunction over-expression of collagen ${ }^{10}$. Recently, several studies have shown that galectin-3 is not just an innocent onlooker but a pivotal player in the pathophysiology of heart failure, in which inhibition of galectin-3 in several models of heart fail- 
ure could reverse heart fibrosis ${ }^{11-14}$. As a biomarker, galectin-3 showed potential value in the prognostication of HF patients ${ }^{15}$. Indeed, van Kimmenade et al. also showed that galectin-3 surpassed NT-proBNP in predicting 60-day mortality and rehospitalization ${ }^{16}$. Recently, the American Heart Association guidelines have included the recommendation at class IIb to assess galectin-3 level either for prognosis or risk stratification in chronic and acute heart failure patients ${ }^{4,17}$. However, data regarding the capacity of galectin-3 to predict all-cause mortality in AHF patients, especially in the Asian population, are scarce. We only found a single study including Chinese hospitalized patients with acute heart failure which showed that the utility of galectin-3 alone as a prognostic factor was not statistically significant for predicting the sudden or in-hospital death ${ }^{18}$. A few other reports investigated 30-day, 60-day and all-cause mortality following an episode of acute heart failure, but they used serial galectin-3 measurements ${ }^{16,19,20}$. We designed this study to investigate whether plasma galectin-3 measured at the time of admission could allow oneyear mortality prediction. Our study was carried out to provide further evidence and a better understanding of the predictive ability of galectin- 3 in the Vietnamese population.

\section{METHODS}

\section{Study design}

This cohort study was conducted in the Department of Cardiology, Cho Ray Hospital, Ho Chi Minh City, Vietnam. We recruited 117 consecutive patients diagnosed with acute heart failure from March 2018 to July 2018, based on the European Society of Cardiology (ESC) criteria ${ }^{3}$. Interventions, treatments, and discharge were carried out according to the hospital protocols. The study was conducted in compliance with the Declaration of Helsinki. The Ethical Committees of Cho Ray Hospital approved it on February $12^{\text {th }}, 2018$ with the number of approval letters being 63/DHYD-HD. All subjects or relatives signed a written informed consent to participate in the present study.

For each subject in our study, epidemiological characteristics were recorded, which included demographic variables (age and sex), comorbidities and risk factors (hypertension, smoking, diabetes, atrial fibrillation, ischemic heart disease, and previous episodes of acute heart failure), body mass index, New York Heart Association function status, signs (systolic pressure, diastolic pressure, heart rate, peripheral edema, pulmonary rales), estimated glomerular filtration rate, biomarkers (galectin-3, BNP, troponin
I, and albumin), and echocardiographic parameters (left ventricular ejection fraction; LVEF). The estimated glomerular filtration rate (eGFR) was calculated according to the 2009 CKD-EPI (Chronic Kidney Disease Epidemiology Collaboration) creatinine equation: eGFR $\left(\mathrm{mL} / \mathrm{min} / 1.73 \mathrm{~m}^{2}\right)=141 \times$ $\min (\text { serum creatinine }[\mathrm{mg} / \mathrm{dL}] / \kappa, 1)^{\alpha} \times \max ($ serum creatinine $[\mathrm{mg} / \mathrm{dL}] / \kappa, 1)^{-1.209} \times 0.993^{\text {age }} \times 1.108$ [if female] $\times 1.159$ [if black], with $\kappa=0.7$ (female) or 0.9 (male), $\alpha=-0.329$ (female) or -0.411 (male), and age in years ${ }^{21}$. All biochemical parameters and biomarkers measurements were performed at the time of admission. The quantitative two-dimensional (biplane Simpson) method was used to measure left ventricular ejection fraction (LVEF) during the hospital stay. We followed up patients for one year from hospitalization to investigate and assess one-year all-cause mortality, which was the endpoint of the study.

\section{Galectin-3, BNP, Troponin I, and Albumin assay}

At the time of admission, blood samples were collected into tubes containing ethylenediaminetetraacetic acid and then transported to the Biochemistry Department of Cho Ray Hospital to be processed and frozen at $-80^{\circ} \mathrm{C}$ for eventual measurements of galectin-3, BNP, troponin I, and albumin. Galectin3 was analyzed using ARCHITECT galectin-3 assay, which is a two-step immunoassay procedure (ARCHITECT galectin-3, Abbott, Park, IL, USA) on the Architect i2000SR analyzer (Abbott Laboratories, Park, IL, USA), according to the manufacturer's instructions ${ }^{22}$. BNP was analyzed using ARCHITECT BNP (ARCHITECT BNP, Abbott) assay on the Architect i2000SR analyzer (Abbott Laboratories). Troponin I was analyzed using chemiluminescent microparticle immunoassay on the ADVIA Centaur XP analyzer (Siemens Diagnostics, Tarrytown, NY, USA). Albumin was analyzed using the colorimetric method on the ADVIA 1800 analyzer (Siemens Diagnostics, Tarrytown, NY, USA).

\section{Statistical analysis}

Continuous variables were presented as mean and standard deviation (SD) for the quantitative variables or as median and interquartile range (IQR) for those without a normal distribution, and as absolute values and percentages for the qualitative variables. Pairwise comparisons between patients with acute heart failure achieving or not achieving the endpoint were performed using the Student's T-test or non-parametric Mann-Whitney $\mathrm{U}$ test for continuous variables, or 
chi-square test or Fisher's exact test for categorical variables, where appropriate. Univariable logistic regression was used to evaluate how well galectin-3 and BNP predicted the outcomes. We then used the multivariable logistic regression for the covariates of galectin-3, BNP, and other factors in predicting the outcomes. The variable selection was performed with Bayesian model averaging (BMA) $\operatorname{method}^{23}$. Receiver-operating characteristic (ROC) curves were also derived to evaluate the performance of galectin3, BNP, and troponin I for predicting the endpoint in patients with acute heart failure. Differences were considered as statistically significant with a p-value less than 0.05 , or when the $95 \%$ CI of the HR excluded the value of 1 . All analyses were conducted using the Rstudio version 1.2 (PBC, Boston, MA).

\section{RESULTS}

\section{Patient characteristics}

A total of 117 patients diagnosed with acute heart failure were included in the study. Six patients (5\%) were lost to follow-up, and fifty-nine patients (53.2\%) died within one year after hospital admission. The clinical and analytical characteristics of patients with acute heart failure are presented in Table 1. The median (IQR) plasma level of galectin-3 in patients with acute heart failure was $34.6 \mathrm{ng} / \mathrm{mL}$ (26.7 - 44.1). Approximately $74 \%$ of patients with acute heart failure had a prior history of chronic heart failure and coronary artery disease.

\section{Correlation of Galectin-3 and other biomarkers with one-year mortality}

A total 59 AHF patients died within one year after hospital admission. In predicting one-year mortality, it was found that galectin-3 level in the deceased group was significantly higher than that in the alive group (Figure 1). Differences in demographic, medical history, and biomarker characteristics between the alive and deceased groups are presented in Table 2. In addition to the difference in galectin-3 levels, patients reaching the endpoint within one year after hospitalization showed a statistically significant difference in age $(\mathrm{p}=0.018)$, eGFR $(\mathrm{p}=0.001)$, plasma troponin I $(\mathrm{p}=0.016)$, albumin $(\mathrm{p}=0.010)$ and BNP $(\mathrm{p}=$ 0.001). We use Cox regression to evaluate the effect of some characteristics, including plasma galectin-3, on one-year mortality as seen in Table 3. Univariate cox regression analysis showed that increased plasma galectin-3 levels had an HR of 3.47 (95\% CI, 2.07 5.83 ; $\mathrm{p}<0.001)$ for one-year mortality. After adjustment for age, eGFR, plasma troponin I, albumin, and

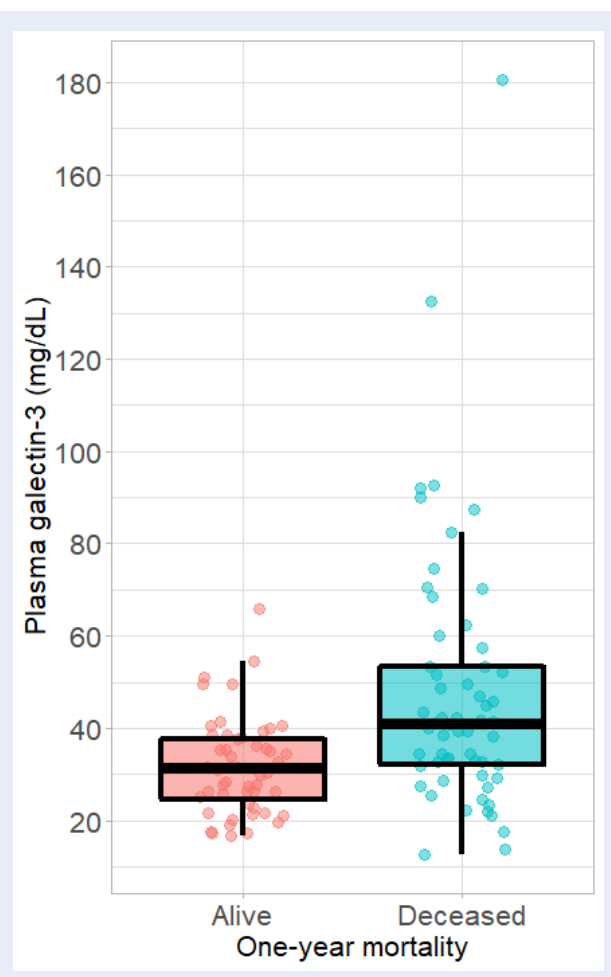

Figure 1: Plasma galectin-3 concentrations in the alive and deceased patients. Box plots showing the plasma galectin-3 levels in the alive and deceased patients (A) during hospitalization and (B) within one year of hospital admission. The upper and lower edges of each box represent the interquartile range $\left(25^{t h}-75^{\text {th }}\right.$ percentile) while the middle line is corresponding to the median. The points are the actual values of plasma galectin-3 level and colored by alive (in red) and deceased (in blue) patients.

BNP, the increased plasma galectin-3 levels had an HR of 2.60 (95\% CI, $1.47-4.60$; p <0.001), implying the independent prognostic ability of galectin- 3 . Our ROC curve analysis showed that plasma galectin3 alone was a good prognostic factor for one-year mortality with the AUC (95\% CI) of 0.71 (0.62 0.81) (Figure 2A). BNP and troponin I alone were not strong prognostic factors, with AUCs $(95 \% \mathrm{CI})$ of $0.69(0.59-0.79)$ and $0.63(0.53-0.74)$, respectively (Figure 2B, C). The optimal cut-off value for galectin3 for predicting one-year all-cause mortality was 40.75 $\mathrm{ng} / \mathrm{mL}$, with a sensitivity of $50.1 \%$ and a specificity of $88.5 \%$. Furthermore, the AUC (95\% CI) for the combined biomarkers (galectin-3 + BNP) was 0.78 (0.70 - 0.86), which was higher than the AUC of galectin-3 alone (Figure 2D). Based on the Kaplan-Meier analyses, patients with elevated galectin-3 and BNP had the highest rates of death, while patients with no elevated 
Table 1: Clinical characteristics of patients with acute heart failure

\begin{tabular}{|c|c|}
\hline Characteristics & $\begin{array}{l}\text { Summary statistic } \\
(N=117)\end{array}$ \\
\hline Age (year), mean $\pm \mathrm{SD}$ & $66.2 \pm 17.5$ \\
\hline Gender male, n (\%) & $65(55.6 \%)$ \\
\hline Smoking, n (\%) & $57(48.7 \%)$ \\
\hline Hypertension, n (\%) & $73(62.4 \%)$ \\
\hline Diabetes, n (\%) & $36(30.8 \%)$ \\
\hline Atrial fibrillation, $\mathrm{n}(\%)$ & $11(9.4 \%)$ \\
\hline Coronary artery disease, $\mathrm{n}(\%)$ & $85(72.6 \%)$ \\
\hline Chronic heart failure, $\mathrm{n}(\%)$ & $86(73.5 \%)$ \\
\hline Prior acute heart failure, $\mathrm{n}(\%)$ & $63(53.8 \%)$ \\
\hline BMI $\left(\mathrm{kg} / \mathrm{m}^{2}\right)$, median (IQR) & $22.0(19.7,23.9)$ \\
\hline Systolic blood pressure (mmHg), median (IQR) & $110(100,120)$ \\
\hline Diastolic blood pressure (mmHg), median (IQR) & $70(60,75)$ \\
\hline Heart rate (beats per minute), median (IQR) & $90(80,100)$ \\
\hline \multicolumn{2}{|l|}{ NYHA classification, $\mathrm{n}(\%)$} \\
\hline - Grade I & $0(0.0 \%)$ \\
\hline - Grade II & $45(38.5 \%)$ \\
\hline - Grade III & $59(50.4 \%)$ \\
\hline - Grade IV & $13(11.1 \%)$ \\
\hline Leg edema & $64(54.7 \%)$ \\
\hline Pulmonary rales & $43(36.8 \%)$ \\
\hline eGFR $\left(\mathrm{ml} / \mathrm{min} / 1.73 \mathrm{~m}^{2}\right)$, median (IQR) & $49.6(33.9,61.9)$ \\
\hline Ejection fraction (\%), median (IQR) & $27(20,33.5)$ \\
\hline Plasma albumin level (g/dl) median (IQR) & $3.3(3.0,3.6)$ \\
\hline Plasma troponin I level (ng/ml) median (IQR) & $0.79(0.09,7.85)$ \\
\hline Plasma BNP level (pg/ml), mean \pm SD & $2675.3 \pm 1263.2$ \\
\hline Plasma galectin-3 level (ng/ml), median (IQR) & $34.6(26.7,44.1)$ \\
\hline 1-year lost to follow-up & $6(5.0 \%)$ \\
\hline 1-year mortality, n (\%) & $59(53.2 \%)$ \\
\hline
\end{tabular}

BMI: Body mass index; BNP: Brain natriuretic peptide; eGFR: estimated glomerular filtration rate; IQR: interquartile range; NYHA: New York Heart Association Functional Classification; SD: standard deviation 
Table 2: Characteristics of the alive and deceased patients within one year from hospital admission

\begin{tabular}{|c|c|c|c|}
\hline \multirow[t]{2}{*}{ Characteristics } & \multicolumn{3}{|c|}{ One-year all-cause mortality } \\
\hline & $\begin{array}{c}\text { No } \\
(\mathrm{N}=52)\end{array}$ & $\begin{array}{c}\text { Yes } \\
(\mathrm{N}=59)\end{array}$ & p value \\
\hline Age (year), mean $\pm S D$ & $63.1 \pm 18.4$ & $70.7 \pm 14.9$ & 0.018 \\
\hline Gender male, n (\%) & $30(57.7 \%)$ & $30(50.8 \%)$ & 0.470 \\
\hline Smoking, n (\%) & $25(48.1 \%)$ & $29(49.2 \%)$ & 0.910 \\
\hline Hypertension, n (\%) & $31(59.6 \%)$ & $39(66.1 \%)$ & 0.480 \\
\hline Diabetes, n (\%) & $12(23.1 \%)$ & $21(35.6 \%)$ & 0.150 \\
\hline Atrial fibrillation, $\mathrm{n}(\%)$ & $8(15.4 \%)$ & $3(5.1 \%)$ & 0.070 \\
\hline Coronary artery disease, $\mathrm{n}(\%)$ & $39(75 \%)$ & $42(71.2 \%)$ & 0.652 \\
\hline Chronic heart failure, $\mathrm{n}(\%)$ & $37(71.2 \%)$ & $44(74.6 \%)$ & 0.685 \\
\hline Prior acute heart failure, n (\%) & $27(51.9 \%)$ & $33(55.9 \%)$ & 0.672 \\
\hline Systolic blood pressure, median (IQR) & $120(100,120)$ & $110(100,120)$ & 0.513 \\
\hline $\begin{array}{l}\text { Diastolic blood pressure, median } \\
\text { (IQR) }\end{array}$ & $70(60,70)$ & $70(60,80)$ & 0.884 \\
\hline $\begin{array}{l}\text { Heart rate (beats per minute), median } \\
\text { (IQR) }\end{array}$ & $90(80,100)$ & $90(80,109)$ & 0.319 \\
\hline $\begin{array}{l}\text { eGFR }\left(\mathrm{ml} / \mathrm{min} / 1.73 \mathrm{~m}^{2}\right), \text { median } \\
(\mathrm{IQR})\end{array}$ & $56.9(36.5,63.9)$ & $41.8(30.3,55.7)$ & 0.001 \\
\hline Ejection fraction (\%), median (IQR) & $27.5(20,34)$ & $26(20,33)$ & 0.703 \\
\hline $\begin{array}{l}\text { Plasma albumin level }(\mathrm{g} / \mathrm{dL}) \text {, median } \\
\text { (IQR) }\end{array}$ & $3.4(3.0,3.8)$ & $3.2(3.0,3.5)$ & 0.010 \\
\hline $\begin{array}{l}\text { Plasma troponin I level (ng/mL), me- } \\
\text { dian (IQR) }\end{array}$ & $0.2(0.1,2.4)$ & $1.2(0.2,10.4)$ & 0.016 \\
\hline $\begin{array}{l}\text { Plasma BNP level }(\mathrm{pg} / \mathrm{mL}) \text {, mean } \pm \\
\text { SD }\end{array}$ & $2267.6 \pm 1131.3$ & $3069 \pm 1264.3$ & 0.001 \\
\hline $\begin{array}{l}\text { Plasma Galectin-3 level (ng/mL), me- } \\
\text { dian (IQR) }\end{array}$ & $31.2(24.1,38)$ & $41.1(31.9,53.5)$ & $<0.001$ \\
\hline
\end{tabular}

markers had the lowest rates (Figure 3).

\section{DISCUSSION}

Our study showed that galectin-3 could predict oneyear all-cause mortality with an area under the ROC curve of 0.71 (95\% CI, $0.62-0.81)$, whereas BNP and troponin I were inferior to galectin-3 with AUCs (95\% CI) of $0.69(0.59-0.79)$ and $0.63(0.53-0.74)$, respectively. Moreover, the combination of galectin-3 and BNP resulted in an improved prognostic value for one-year mortality with AUC of 0.78 (95\% CI, 0.70 $0.86)$.

Previous studies have investigated the contribution of galectin-3 in the pathogenic process of heart failure. Nguyen et al. suggested that the major factors con- tributing to the cardiac release of galectin-3 and elevated circulating levels of galectin- 3 are cardiac inflammation and enhanced activation of $\beta$-adrenergic receptors ${ }^{24}$. Several studies have assessed the diagnostic capacity of galectin-3 and compared it to natriuretic peptides (BNP and NT-proBNP) in identifying acute heart failure patients. For example, van Kimmenade et al. revealed that AUC of NT-proBNP was 0.94 for HF diagnosis in dyspneic patients, whereas the AUC of galectin-3 was $0.74^{16}$. Recently, studies have focused on discovering biomarkers of diagnostic capability in HF to biomarkers of prognostic value.

Our findings were supported by several studies that reported the usefulness of galectin-3 as a risk predictor of mortality in AHF patients. A large cohort 
Table 3: Cox regression model for one-year mortality with linear effect of Galectin-3

\begin{tabular}{|c|c|c|c|c|c|c|}
\hline \multirow[b]{3}{*}{$\begin{array}{l}\text { Galectin-3 } \\
(\mathrm{ng} / \mathrm{ml})\end{array}$} & \multicolumn{3}{|c|}{ Univariable analysis } & \multicolumn{3}{|c|}{ Multivariable analysis } \\
\hline & HR & 95\% CI & P value & HR & $95 \%$ CI & P value \\
\hline & & & & & & \\
\hline - Galectin-3 $\leq 40.75$ & 1 & - & Ref & 1 & - & Ref \\
\hline - Galectin-3 > 40.75 & 3.47 & $2.07-5.83$ & $<0.001$ & 2.60 & $1.47-4.60$ & 0.001 \\
\hline Age (year) & 1.02 & $1-1.04$ & 0.027 & 1.006 & $0.99-1.03$ & 0.524 \\
\hline $\begin{array}{l}\text { eGFR } \\
\left(\mathrm{ml} / \mathrm{min} / 1.73 \mathrm{~m}^{2}\right)\end{array}$ & 0.98 & $0.96-0.99$ & 0.006 & 0.99 & $0.98-1.01$ & 0.318 \\
\hline Albumin (g/dL) & 0.45 & $0.27-0.76$ & 0.003 & 0.51 & $0.27-0.96$ & 0.037 \\
\hline Troponin I (ng/mL) & 1 & $1-1.005$ & 0.090 & 1 & $0.99-1.005$ & 0.108 \\
\hline $\mathrm{BNP}(\mathrm{pg} / \mathrm{mL})$ & 1 & $1-1.001$ & 0.002 & 1 & $1-1$ & 0.185 \\
\hline
\end{tabular}
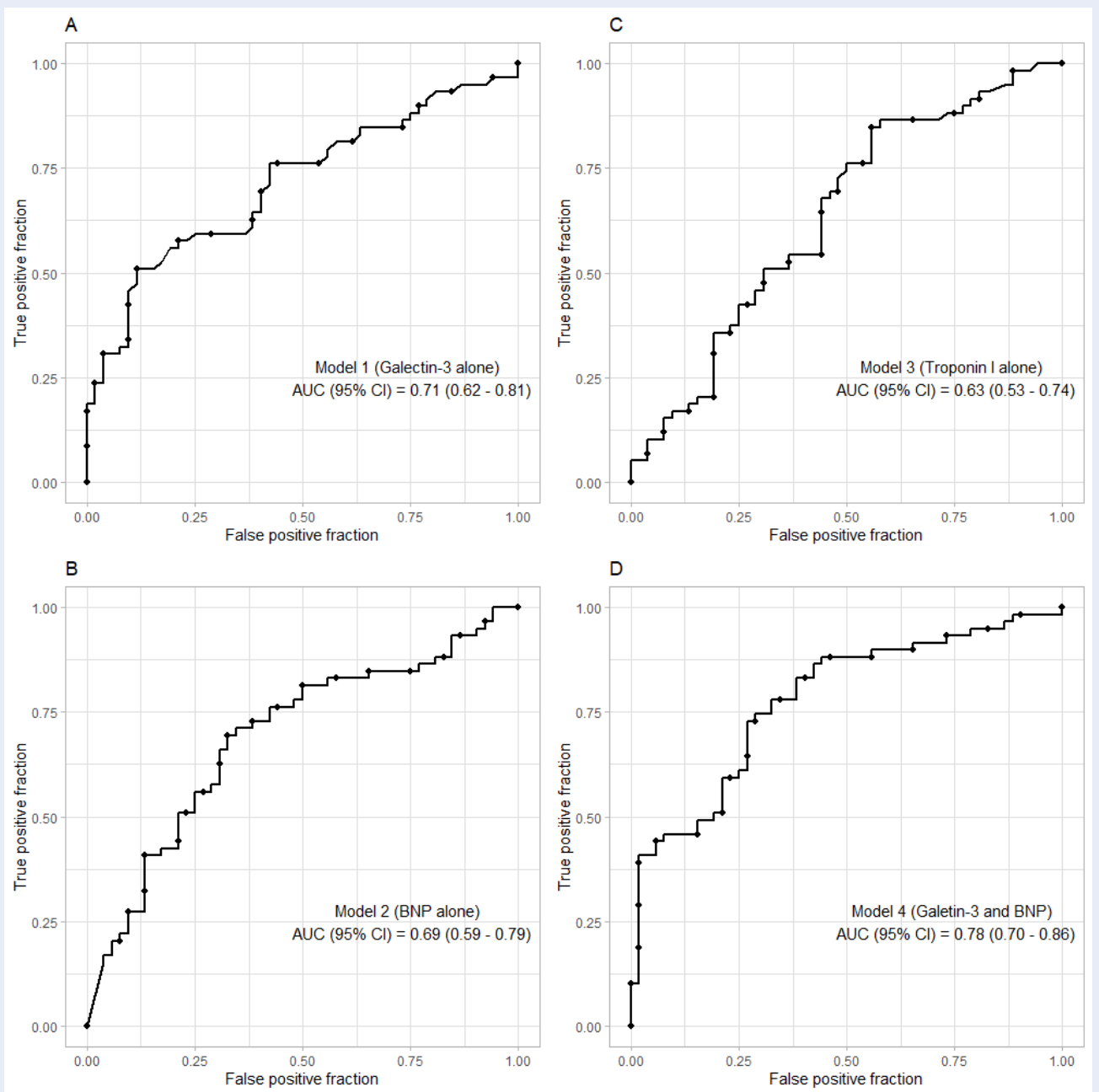

Figure 2: Receiver operating characteristic (ROC) curves for prediction of one-year all-cause mortality. Area under the curve of ROC (with the $95 \%$ confidence interval) for the prediction of one-year mortality for (A) galectin3, (B) BNP, (C) Troponin I, and (D) Galectin-3 + BNP. 


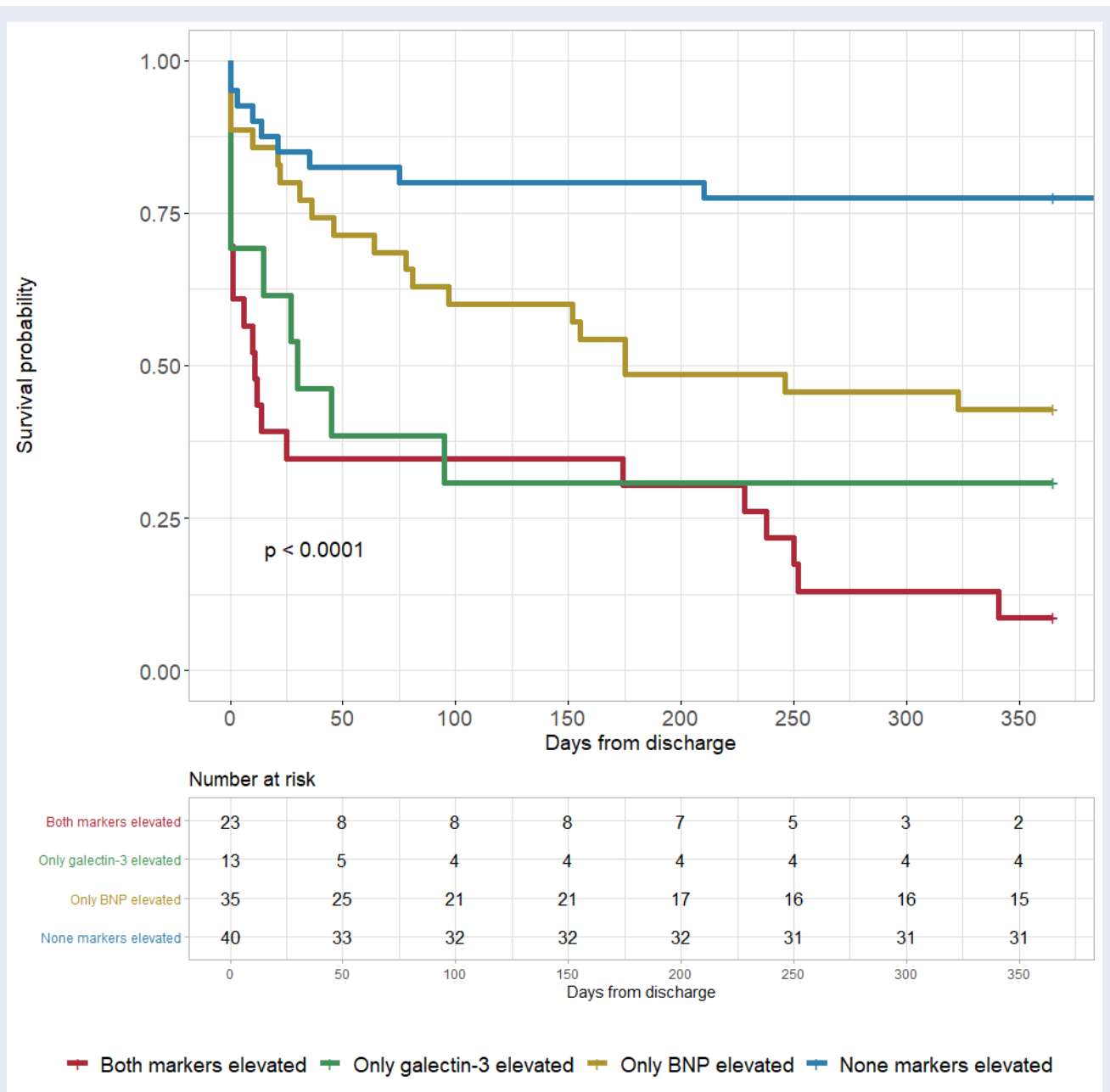

Figure 3: Kaplan-Meier curve showed that acute heart failure patients with a plasma galectin-3 level more than $40.75 \mathrm{ng} / \mathrm{mL}$ and brain-natriuretic peptide level above the optimal cut-point $2549 \mathrm{pg} / \mathrm{mL}$ were associated with higher rates of mortality than either of the two markers alone.

study that included 1140 hospitalized heart failure patients showed that galectin-3 had a good prognostic value for in-hospital mortality with AUC of 0.71 $(95 \% \text { CI, } 0.65-0.77)^{18}$. Besides, combining galectin3 and another biomarker (NT-proBNP) resulted in an improved AUC of 0.81 (95\% CI, $0.76-0.86)$. Another study by van Kimmenade et al. ${ }^{16}$ showed that galectin-3 represents a remarkable biomarker for predicting 60-day all-cause death in 209 AHF patients admitted to the emergency setting. This study also displayed that increased levels of galectin- 3 had an OR of 14.3 (95\% CI, 5.6 - 45.1; p < 0.001) after adjustment for age, glomerular filtration rate, and New York Heart Association (NYHA) functional classification. Therefore, the authors concluded that galectin-3 was an independent prognostic factor for 60-day mortality and rehospitalization.

Similarly, Miró et al. ${ }^{25}$ showed that galectin-3 has a superior prognostic value (AUC $=0.732, \mathrm{p}=0.041$ ) for predicting the 30-day mortality in $115 \mathrm{AHF}$ patients compared to NT-proBNP (AUC $=0.586, \mathrm{p}=$ $0.446)$ and troponin $\mathrm{I}(\mathrm{AUC}=0.639, \mathrm{p}=0.222)$. Miró et al. also showed that the concentrations of galectin3 could be applicable for risk stratification of shortterm mortality in the emergency setting. For example, patients with galectin-3 levels between $30-42 \mu \mathrm{g} / \mathrm{L}$ had an OR of 5.25 (95\% CI, 0.53 - 51.63), whereas those with galectin-3 levels $>42 \mu \mathrm{g} / \mathrm{L}$ had an OR of 8.88 (95\% CI, 1.49 - 52.73).

Intriguingly, Demissei et al. ${ }^{26}$ showed that the AUCs of galectin-3 measured at admission, day 3, day 7 , and day 14 did not have any statistical difference in pre- 
dicting the 180-day mortality in 2023 AHF patients. The serial measurement of galectin-3 during a hospital stay is not recommended. Accordingly, galectin-3 was measured only once for each patient in the study and at the time of admission in our study. To our knowledge, this is the first study assessing the prognostic ability of galectin-3 in predicting the long-term mortality in AHF patients in the Vietnamese population and the second in the Asian population. However, one of the limitations is the small sample size of AHF patients included in our study, which could have introduced a type II error. Besides, there was no matching control group to compare the circulatory levels of galectin-3 with the AHF group. Our study also did not assess the diagnostic capacity of galectin-3 in patients with AHF. Therefore, further studies with a more significant number of patients enrolled are warranted to evaluate the diagnostic and long-term prognostic utility of combining galactin3 with other biomarkers, i.e., soluble ST2 and highsensitivity (hs) troponin.

\section{CONCLUSION}

Galectin-3 measured at the time of admission showed an excellent prognostic capacity to predict one-year all-cause mortality in patients with acute heart failure. The results of our study support the utility of a combined galectin-3 and BNP model as a risk predictor of long-term mortality in AHF patients.

\section{ABBREVIATIONS}

AHF: acute heart failure

AUC: area under the curve

BMA: Bayesian model averaging

BNP: brain natriuretic peptide

CKD-EPI: Chronic Kidney Disease Epidemiology

Collaboration

eGFR: Estimated glomerular filtration rate

HF: heart failure

IQR: inter quartile range

LVEF: left ventricular ejection fraction

NT-proBNP: N-terminal pro-brain natriuretic peptide

NYHA: New York Heart Association

ROC: Receiver-operating characteristic

SD: standard deviation

\section{ACKNOWLEDGMENTS}

We thank the Ethical Committees of University of Medicine and Pharmacy at Ho Chi Minh city and Cho Ray hospital for approving this study; we thank Dr. Tran Thanh Vinh, head of Biochemistry Department of Cho Ray hospital, for performing galectin-3 and other biomarker assays; we thank Ms. Huynh Thi Lien Nga and Mr Dang Quang Loi for supporting this study.

\section{AUTHOR'S CONTRIBUTIONS}

Conceptualization and Methodology: H.V.S., D.Q.T, C.N.H; Data collection: H.V.S., D.Q.T., T.T.T.H.; Analysis: H.V.S., D.Q.T.; Writing original draft preparation: H.V.S., D.Q.T., T.T.T.H., C.N.H., T.T.T.; Writing, review, editing: H.V.S, D.Q.T. All authors read and approved the final manuscript.

\section{FUNDING}

This research did not receive any specific grant from funding agencies in the public, commercial, or notfor-profit sectors.

\section{AVAILABILITY OF DATA AND MATERIALS}

Data and materials used and/or analyzed during the current study are available from the corresponding author on reasonable request.

\section{ETHICS APPROVAL AND CONSENT TO PARTICIPATE}

This study was conducted in accordance with the amended Declaration of Helsinki. The institutional review board of Cho Ray hospital approved the study with the number of approval letter being 63/DHYD$\mathrm{HD}$, and all participants provided written informed consent.

\section{CONSENT FOR PUBLICATION}

Not applicable.

\section{COMPETING INTERESTS}

The authors declare that they have no competing interests.

\section{REFERENCES}

1. Savarese G, Lund LH. Global Public Health Burden of Heart Failure. Card Fail Rev. 2017;3(1):7-11. PMID: 28785469. Available from: 10.15420/cfr.2016:25:2.

2. Ibrahim NE, Januzzi JL. Established and Emerging Roles of Biomarkers in Heart Failure. Circ Res. 2018;123(5):614-29. PMID: 30355136. Available from: 10.1161/CIRCRESAHA.118. 312706.

3. Ponikowski P, Voors AA, Anker SD, Bueno H, Cleland JG, Coats AJ, et al. 2016 ESC Guidelines for the diagnosis and treatment of acute and chronic heart failure: the Task Force for the diagnosis and treatment of acute and chronic heart failure of the European Society of Cardiology (ESC). Developed with the special contribution of the Heart Failure Association (HFA) of the ESC. Eur J Heart Fail. 2016;18(8):891-975. PMID: 27207191. Available from: 10.1002/ejhf.592. 
4. Yancy CW, Jessup M, Bozkurt B, Butler J, Casey DE, Colvin MM. 2017 ACC/AHA/HFSA Focused Update of the 2013 ACCF/AHA Guideline for the Management of Heart Failure: A Report of the American College of Cardiology/American Heart Association Task Force on Clinical Practice Guidelines and the Heart Failure Society of America. Circulation. 2017;136(6):e137-61. PMID: 28455343. Available from: 10. 1161/CIR.0000000000000509.

5. de Boer RA, Daniels LB, Maisel AS, Januzzi JL. State of the Art: newer biomarkers in heart failure. Eur J Heart Fail. 2015;17(6):559-69. PMID: 25880523. Available from: 10.1002/ ejhf.273.

6. Schou M, Gustafsson F, Kjaer A, Hildebrandt PR. Long-term clinical variation of NT-proBNP in stable chronic heart failure patients. Eur Heart J. 2007;28(2):177-82. PMID: 17218450. Available from: 10.1093/eurheartj/ehl449.

7. Thygesen K, Mair J, Mueller C, Huber K, Weber M, Plebani M, et al. Recommendations for the use of natriuretic peptides in acute cardiac care: a position statement from the Study Group on Biomarkers in Cardiology of the ESC Working Group on Acute Cardiac Care. Eur Heart J. 2012;33(16):2001-6. PMID: 21292681. Available from: 10.1093/eurheartj/ehq509.

8. Suthahar N, Meijers WC, Silljé HH, Ho JE, Liu FT, de Boer RA Galectin-3 Activation and Inhibition in Heart Failure and Cardiovascular Disease: an Update. Theranostics. 2018;8(3):593609. PMID: 29344292. Available from: 10.7150/thno.22196.

9. Li LC, Li J, Gao J. Functions of galectin-3 and its role in fibrotic diseases. J Pharmacol Exp Ther. 2014;351(2):336-43. PMID: 25194021. Available from: 10.1124/jpet.114.218370.

10. Sharma UC, Pokharel S, van Brakel TJ, van Berlo JH, Cleutjens JP, Schroen B. Galectin-3 marks activated macrophages in failure-prone hypertrophied hearts and contributes to cardiac dysfunction. Circulation. 2004;110(19):3121-8. PMID: 15520318. Available from: 10.1161/01.CIR.0000147181.65298. $4 \mathrm{D}$.

11. Calvier L, Martinez-Martinez E, Miana M, Cachofeiro V, Rousseau E, Sádaba JR. The impact of galectin-3 inhibition on aldosterone-induced cardiac and renal injuries. JACC Heart Fail. 2015;3(1):59-67. PMID: 25458174. Available from: 10. 1016/j.jchf.2014.08.002.

12. Nguyen $M N$, Ziemann $M$, Kiriazis $H$, Su $Y$, Thomas $Z$, Lu Q. Galectin-3 deficiency ameliorates fibrosis and remodeling in dilated cardiomyopathy mice with enhanced Mst1 signaling. Am J Physiol Heart Circ Physiol. 2019;316(1):45-60. PMID: 30387702. Available from: 10.1152/ajpheart.00609.2018.

13. Vergaro G, Prud'homme M, Fazal L, Merval R, Passino C, Emdin M. Inhibition of Galectin-3 Pathway Prevents IsoproterenolInduced Left Ventricular Dysfunction and Fibrosis in Mice. Hypertension. 2016;67(3):606-12. PMID: 26781273. Available from: 10.1161/HYPERTENSIONAHA.115.06161.

14. Yu L, Ruifrok WP, Meissner M, Bos EM, van Goor H, Sanjabi B. Genetic and pharmacological inhibition of galectin-3 prevents cardiac remodeling by interfering with myocardial fibrogenesis. Circ Heart Fail. 2013;6(1):107-17. PMID: 23230309. Available from: 10.1161/CIRCHEARTFAILURE.112.971168.
15. Gehlken C, Suthahar N, Meijers WC, de Boer RA. Galectin-3 in Heart Failure: An Update of the Last 3 Years. Heart Fail Clin. 2018;14(1):75-92. PMID: 29153203. Available from: 10.1016/j. hfc.2017.08.009.

16. van Kimmenade RR, Januzzi JL, Ellinor PT, Sharma UC, Bakke JA, Low AF. Utility of amino-terminal pro-brain natriuretic peptide, galectin-3, and apelin for the evaluation of patients with acute heart failure. J Am Coll Cardiol. 2006;48(6):121724. PMID: 16979009. Available from: 10.1016/j.jacc.2006.03. 061.

17. Yancy CW, Jessup M, Bozkurt B, Butler J, Casey DE, Drazner $\mathrm{MH}$, et al. 2013 ACCF/AHA guideline for the management of heart failure: a report of the American College of Cardiology Foundation/American Heart Association Task Force on practice guidelines. Circulation. 2013;128(16):e240-327. PMID: 23741058. Available from: 10.1161/CIR.0b013e31829e8776.

18. Zhang Y, Zhang R, An T, Huang Y, Guo X, Yin S. The utility of galectin-3 for predicting cause-specific death in hospitalized patients with heart failure. J Card Fail. 2015;21(1):51-9. PMID: 25463412. Available from: 10.1016/j.cardfail.2014.10.006.

19. Sánchez-Serna J, Pérez-Martínez MT, Asensio-López MC Casas T, Noguera JA, Pascual-Figal DA. Short-term Serial Measurement of Galectin-3 in Hospitalized Patients With Acute Heart Failure. Rev Esp Cardiol (Engl Ed). 2018;71(5):401-2. PMID: 28473265. Available from: 10.1016/j.rec.2017.03.013.

20. van Vark LC, Lesman-Leegte I, Baart SJ, Postmus D, Pinto YM, de Boer RA, et al. Prognostic Value of Serial Galectin-3 Measurements in Patients With Acute Heart Failure. J Am Heart Assoc. 2017;6(12):e003700. PMID: 29187387. Available from: 10.1161/JAHA.116.003700

21. Levey AS, Stevens LA, Schmid CH, Zhang YL, Castro AF, Feldman $\mathrm{HI}$, et al. A new equation to estimate glomerular filtration rate. Ann Intern Med. 2009;150(9):604-12. PMID: 19414839. Available from: 10.7326/0003-4819-150-9-200905050-00006.

22. La'ulu SL, Apple FS, Murakami MM, Ler R, Roberts WL, Straseski JA. Performance characteristics of the ARCHITECT Galectin-3 assay. Clin Biochem. 2013;46(1-2):119-22. PMID: 23010446. Available from: 10.1016/j.clinbiochem.2012.09.014.

23. Hoeting JA, Madigan D, Raftery AE, Volinsky CT. Bayesian Model Averaging: A Tutorial. Stat Sci. 1999;14(4):382-401.

24. Nguyen MN, Su Y, Vizi D, Fang L, Ellims AH, Zhao WB. Mechanisms responsible for increased circulating levels of galectin-3 in cardiomyopathy and heart failure. Sci Rep. 2018;8(1):8213. PMID: 29844319. Available from: 10.1038/s41598-018-26115y.

25. Miró O, de la Presa BG, Herrero-Puente P, Bonifacio RF, Möckel $M$, Mueller $C$. The GALA study: relationship between galectin3 serum levels and short- and long-term outcomes of patients with acute heart failure. Biomarkers. 2017;22(8):731-9. PMID: 28406038. Available from: 10.1080/1354750X.2017.1319421.

26. Demissei BG, Valente MA, Cleland JG, O'Connor CM, Metra $M$, Ponikowski $P$. Optimizing clinical use of biomarkers in high-risk acute heart failure patients. Eur J Heart Fail. 2016;18(3):269-80. PMID: 26634889. Available from: 10.1002/ ejhf.443. 